\title{
Learning outcomes of children with teacher-identified emerging health and developmental needs
}

\author{
Meredith O’Connor DEdPsych, ${ }^{1,2,3}$ \\ meredith.oconnor@mcri.edu.au
}

\author{
Shiau Chong $\mathrm{PhD}{ }^{1}$ \\ shiau.chong@mcri.edu.au
}

Jon Quach PhD, ${ }^{1,4}$

jon.quach@mcri.edu.au

\section{Sharon Goldfeld PhD, FRACP (corresponding author) ${ }^{1,2}$ sharon.goldfeld@rch.org.au}

Author affiliations: ${ }^{1}$ Centre for Community Child Health, Murdoch Childrens Research Institute, Royal Children's Hospital, Melbourne, Australia; ${ }^{2}$ Department of Paediatrics, University of Melbourne, Melbourne, Australia; ${ }^{3}$ ANU College of Arts \& Social Sciences, The Australian National University; ${ }^{4}$ Melbourne Graduate School of Education, The University of Melbourne, Australia

Address correspondence to: Professor Sharon Goldfeld, Centre for Community Child Health, Royal Children's Hospital, 2 East Clinical Offices, 50 Flemington Road, Parkville, 3052, Victoria, Australia. Email: Sharon.Goldfeld@rch.org.au. Phone: +61 39345 6408. Fax: +61393455900.

Running head: Learning outcomes and emerging additional needs

Conflicts of interest: None to declare.

Main text word count: 3108

\section{Abstract word count: 263}

Acknowledgements: This project was funded by the Murdoch Children's Research Institute Population Health Theme, and was supported by the Victorian Government's Operational Infrastructure Support Program. Prof Goldfeld is supported by Australian National Health and Medical Research Council (NHMRC) Career Development Fellowship (1082922). Dr Quach is supported by an Australian Research Council Discovery Early Career Researcher Award (DE140100751). This paper uses data from the Australian Early Development Census (AEDC). The AEDC is funded by the Australian Government Department of Education and Training (DET). The findings and views reported are those of the authors and should not be attributed to the Australian Government or DET.

This is the author manuscript accepted for publication and has undergone full peer review but has not been through the copyediting, typesetting, pagination and proofreading process, which may lead to differences between this version and the Version of Record. Please cite this article as doi: $10.1111 /$ cch.12737 


\begin{abstract}
Objectives: Children's additional health and developmental needs are often first identified by teachers when they begin school. This study estimates the Grade 3 literacy and numeracy outcomes of children with teacher-identified additional needs emerging in the first year of school, including the added burden conferred by socioeconomic disadvantage.
\end{abstract}

Methods: Population linked data $(\mathrm{N}=42,619)$ was analysed from the Australian Early Development Census, which includes teacher reports on children's health and development at school entry, and the National Assessment Program - Literacy and Numeracy, a direct assessment of reading and numeracy skills at Grade 3. Linear regression analyses were used to estimate associations between emerging needs and learning outcomes, adjusted for sociodemographic characteristics. The combined effect of emerging needs and low maternal education (an indicator of socioeconomic disadvantage) on academic outcomes was examined by estimating the relative excess risk due to interaction (RERI).

Results: Emerging health and developmental needs at school entry was associated with lower reading $(b=-26.86,95 \% \mathrm{CI}=-29.19,-24.52)$ and numeracy $(b=-24.39,95 \% \mathrm{CI}=-26.43,-22.35)$ outcomes at Grade 3. The combined effect of emerging needs and socioeconomic disadvantage was greater than expected when their individual effects are summed (RERI $=0.38,95 \% \mathrm{CI} 0.22,0.55$ for reading and RERI $=0.27,95 \% \mathrm{CI} 0.10,0.43$ for numeracy). Conclusion: In the current study, emerging health and developmental needs identified by teachers at the outset of schooling was associated with poorer literacy and numeracy skills at Grade 3, and family socioeconomic disadvantage appeared to further amplify this effect. Meeting the needs of these children will require timely and coordinated supports across the health and education systems, particularly for those children who are also disadvantaged. 
Keywords: Special health care needs; Special Educational Needs and Disabilities; additional needs; disability; academic achievement; school functioning.

This article is protected by copyright. All rights reserved. 


\section{KEY MESSAGES}

- There is a well-established relationship between children's health and learning pathways.

- Children who begin school with emerging health and developmental needs identified by their teachers on average have poorer learning outcomes by Grade 3 .

- When emerging health and developmental needs are combined with socioeconomic disadvantage, this effect is amplified.

- Meeting the needs of these children will require effective, coordinated supports across the health and education systems. 


\section{INTRODUCTION}

By the time they enter school, the majority of Australian children have at least one ongoing health condition (Liu et al., 2018). Speech and language, emotional and behavioural, and learning difficulties are now the most common issues identified by teachers, with the proportion of children affected increasing over time (O'Connor, O'Connor, Quach, Vashishtha, \& Goldfeld, in press). Many of these difficulties impact on similar areas of children's functioning, such as communication or behaviour, have complex bio-psycho-social aetiology, and necessitate multidisciplinary supports. In this context, a non-categorical approach that considers children's additional health and developmental needs can be of value in shifting focus away from a child's diagnosis and towards their individual support needs (Bethell et al., 2015).

The education system is an important universal platform for meeting children's additional health and developmental needs. Children are exposed to an average of 950 hours of schooling each year, and school professionals regularly administer mediations, provide counselling, implement behavioural intervention plans, and monitor behavioural and emotional issues (Barnard-Brak, Stevens, \& Carpenter, 2017). Recognizing this important role, education systems globally are reviewing how to most effectively and equitably support children with additional needs. This includes countries such as Australia, the United Kingdom, where discussion focuses on children with Special Educational Needs and Disabilities (Department for Education and Skills, 2001), and the United States, under the rubric of Special Health Care Needs (Bethell et al., 2012; Forrest, Bevans, Riley, Crespo, \& Louis, 2011; Reuben \& Pastor, 2013). 
A particular challenge facing education systems is how to support children whose health and developmental difficulties emerge as they transition to school. Teachers play an important role in early identification; the increased social, language, and cognitive demands of the classroom environment often highlight children's need for greater support (O'Connor, Rosema, Quach, Kvalsvig, \& Goldfeld, 2017). In addition, not all health and developmental difficulties that have been identified qualify children for special needs programs, and the degree to which the needs of children who fall outside this scope (18\% of the school entrant population in Australia; O'Connor et al., in press) are recognised and met is unclear (O'Connor et al., 2015). Other countries, such as the US, can similarly face challenges in the timely response to children's emerging needs, given variability in the resources available within and across schools (Barnard-Brak et al., 2017).

For some children with emerging needs, language and learning issues can directly affect their capacity to engage with the mainstream academic curriculum. For others, an impact on learning could occur indirectly via a range of modifiable pathways, such as school absenteeism, lowered expectations, and fatigue or irritability (O'Connor, Howell-Meurs, Kvalsvig, \& Goldfeld, 2015). Data from a small sample $(n=120)$ of children with emerging additional health and developmental needs estimated that these children have three times the odds of experiencing poor learning pathways than their peers (Goldfeld, O'Connor, Quach, Tarasuik, \& Kvalsvig, 2015). Differential learning outcomes have been observed even for conditions with no obvious direct impact on cognitive or neurological functioning, like arthritis or asthma (Pinquart \& Teubert, 2012).

The risk of poor learning outcomes is likely to be amplified in the context of disadvantage. Children with emerging additional needs are overrepresented in more disadvantaged settings 
(O'Connor et al., in press). Yet, following the inverse care law, children living in disadvantaged contexts have less access to the medical, allied health, education and related services that can help to ameliorate these impacts (Dalziel, Huang, Hiscock, \& Clarke, 2018).

The link between health and learning is well-established (Bethell et al., 2012; Forrest et al., 2011; Goldfeld et al., 2015; O'Connor et al., 2015; Pinquart \& Teubert, 2012; Reuben \& Pastor, 2013). However, evidence is lacking about the learning outcomes of children with emerging additional needs at the outset of schooling, particularly for those who are also disadvantaged and less likely to be represented in sample-based studies. To stimulate advocacy and policy action across the health and education systems, we aim to quantify the learning outcomes of children with emerging additional needs in the current environment, including the added burden created by socioeconomic disadvantage. We draw on the population-level data that is needed to raise the visibility of these children, and apply analytic methods that can more robustly capture the combined effect of emerging additional needs and disadvantage. We hypothesize that emerging additional needs at school entry will be associated with poorer learning outcomes by Grade 3, and that socioeconomic disadvantage will further amplify this effect.

\section{METHODS}

\section{Data source}

The Australian Early Development Census (AEDC), an Australian adaptation of the Canadian Early Development Instrument (EDI), is a population census of children's development completed in their first year of school (median age 5 years) (Brinkman, Gregory, Goldfeld, Lynch, \& Hardy, 2014). The AEDC is conducted across Australia once every three years, with a $>95 \%$ response rate, and provides teacher-reported information on 
aspects of children's development, including additional health and developmental needs arising in the school context (Goldfeld et al., 2015).

The National Assessment Program - Literacy and Numeracy (NAPLAN) is a standardized direct assessment of children's academic progress in Grades 3, 5, 7, and 9, implemented nationally across Australia, achieving a $>95 \%$ participation rate. Five academic domains are assessed: reading, writing, spelling, grammar and punctuation, and numeracy (Daraganova, Edwards, \& Sipthorp, 2013). We analysed the reading and numeracy subscales collected at Grade 3 (approximately 9 years of age), because they represent key drivers of future economic productivity.

Children in the Australian State of Victoria who entered Government schools in 2012 had AEDC data linked to the Grade 3 NAPLAN administered in 2015. Government primary schools represent $70 \%$ of schools in the Victorian education system, and cater to a higher proportion of children with additional needs and children from socioeconomically disadvantaged backgrounds. Of 48,463 eligible children, 42,619 (88.0\%) had data successfully matched, and these linked cases were representative of the full Victorian cohort. For example, rates of established and emerging additional needs were $4.80 \%$ and $19.45 \%$ in the matched cases, and $5.2 \%$ and $20.1 \%$ in the full cohort, respectively. This methodology was approved by the University of Melbourne Human Ethics Advisory Group.

\section{Measures}

Exposure: Additional health and developmental needs (additional needs) in the first year of school 
Additional needs in the first year of school (emerging, established, or standard population) was derived from teacher reports in the AEDC. Teacher reports of children's additional needs in the AEDC have been shown to correlate with other developmental indicators as expected (O’Connor, Rosema, Quach, Kvalsvig, \& Goldfeld, 2016), and should be interpreted as an indicator of additional needs as contextualized within the school setting (O'Connor et al., 2017; O’Connor et al., 2016).

Teachers were asked whether the child a) had any area/s of impairment (speech impairment, emotional problems, behavioural problems, visual impairment, hearing impairment, learning disability, physical disability, home environment problems, trauma, or other enduring problems) that in their view impacted the child's ability to do school work in a regular classroom; or b) needed further assessment and/or was currently being assessed due to these difficulties. Where teachers answered "yes" to either or both of these questions, children were categorized as having emerging needs.

Children formally designated as having special needs within the school system were also identified by teachers through the AEDC, based on whether the child was "identified already as high need requiring special assistance due to chronic medical, physical, or intellectually disabling conditions (e.g. Autism, Cerebral Palsy, Down Syndrome).” Any child for which the teacher responded "yes" was categorized as having established needs, irrespective of responses to a) or b) above (i.e., child could only be categorized as established or emerging needs, but not both).

All other children were categorized as belonging to the standard population. 


\section{Outcomes: Reading and numeracy at Grade 3}

For the reading subscale, students were provided with a selection of texts in different writing styles, and answered questions reflecting their comprehension of the content, key messages, and meaning of particular words or phrases. The numeracy subscale focused on core skills within the mathematics curricula, such as number, function, pattern, and mathematical reasoning, with questions requiring short responses or multiple choice answers.

Rasch modelling was used to convert the raw reading and numeracy scores into scaled scores ranging from 0 to 1000 . We used the continuous scaled scores for regression models examining the associations between emerging additional needs and academic outcomes. When examining the combined effects of emerging additional needs and low socioeconomic position on academic outcomes, we dichotomized academic scores into low (lowest performing $20 \%$ within this cohort) and high (top performing $80 \%$ ) for interpretability.

\section{Socio-demographic factors}

Demographic information was obtained from the AEDC data and included the child's age, gender, language background, country of birth, Aboriginal and/or Torres Strait Islander (ATSI) status, and geographic remoteness. The socioeconomic status of the community in which the child lived was assigned using the Socio-Economic Indexes for Areas (SEIFA), which takes into account variables such as average levels of income, educational attainment, and unemployment (Australian Bureau of Statistics, 2013). As no family-level socioeconomic data was available in the AEDC in the first year of school, parent education and occupation were obtained from the NAPLAN data at Grade 3. To examine the combined effect of additional needs and disadvantage, we used low maternal education as a key indicator of 
socioeconomic resources within the family environment (Davis-Kean, 2005), dichotomized as low (high school and below) versus higher (post-high school).

\section{Statistical analysis}

Descriptive statistics were used to characterise this population, including the proportion of children with teacher-identified emerging additional needs.

Linear regression models were then conducted to examine the associations between emerging additional needs and reading and numeracy scores, adjusting for sociodemographic factors. The nested nature of the data was accounted for using robust standard errors, clustering on teacher. A sensitivity analysis was also conducted to discern the degree to which the association between emerging additional needs and academic outcomes was due to cognitive difficulties. Data was used from the Birth cohort (B-cohort; N=5107) of the Longitudinal Study of Australian Children (LSAC) (Soloff, Lawrence, Misson, \& Johnstone, 2006) to replicate analyses using the same AEDC and NAPLAN variables (obtained through data linkage), and additionally adjusting for general cognitive abilities at 4-5 years measured using the Who Am I? (WAI) Instrument (De Lemos \& Doig, 1999).

Next, we examined the combined effect of additional needs and low maternal education on academic outcomes, using the approach outlined by Knol and VanderWeele (2012). The focus of this analysis was whether the combined effect of emerging additional needs and disadvantage was larger than the sum of their individual effects (interaction on the additive scale). Generalized linear models with log-Poisson link function were used to estimate the relative risk (RR) of having a low reading or numeracy score for children in each combination of additional needs (standard population, emerging needs, established needs) by 
maternal education (low education, higher education). The relative excess risk due to interaction (RERI) was estimated, with confidence intervals obtained using the delta method (Hosmer \& Lemeshow, 1992). A RERI greater than 0 indicates that the combined effect of emerging additional needs and low maternal education is greater than expected when their individual effects are summed (VanderWeele \& Knol, 2014).

Multiple imputation by chained equations was used to account for missing data (White, Royston, \& Wood, 2010). The imputation model included all variables in the analysis model and two auxiliary variables (grammar and spelling scores). Twenty imputed datasets were created and the results combined using Rubin's rules. All analyses were conducted using Stata 14.2 (StataCorp, College Station, TX, USA).

\section{RESULTS}

\section{Cohort characteristics}

The cohort was roughly evenly split by gender (51\% male; Table 1). Most children lived in major cities or regional centres (95.2\%), and were born in Australia (93.1\%). Around $20 \%$ of children spoke a language other than English at home (Table 1). The mean reading and numeracy scores were similar to estimates for the full Australian population (Australian Curriculum Assessment and Reporting Authority, 2017).

A substantial proportion (19.5\%) of children were identified by their teacher as having emerging additional health and developmental needs in the first year of school (Table 1). The most common concerns were speech impairment (34\%) and issues associated with the home environment (18\%) (Figure 1). Teachers also indicated that many children with emerging additional needs required further assessment (31\%). 


\section{Emerging additional needs and learning outcomes}

Results from linear regression analyses show that emerging additional needs were associated with a third of a standard deviation lower reading and numeracy scores by Grade 3, after accounting for covariates (Table 2). As a point of comparison, children with established needs had scores lower by nearly half a standard deviation, compared to the standard population. Similar patterns were observed across literacy and numeracy outcomes (Table 2).

Sensitivity analyses conducted with the LSAC sample suggests that this effect is evident even once accounting for cognitive skills at school entry. When additionally adjusting for cognitive skills at school entry, emerging needs were associated with both lower reading ( $b=-$ $25.80,95 \% \mathrm{CI}=-34.17,-17.43)$ and numeracy $(\mathrm{b}=-21.01,95 \% \mathrm{CI}=-27.40,-14.63)$ outcomes (full data not shown).

\section{Combined effect of emerging additional needs and low maternal education}

We found evidence that the combined effect of emerging additional needs and low maternal education was larger than the sum of their individual effects (Tables 3 and 4). This was observed for both reading (RERI $=0.38,95 \%$ CI $0.22,0.55)$ and numeracy (RERI=0.27, 95\% CI $0.10,0.43$ ) outcomes.

\section{DISCUSSION}

Around 1 in 5 children in this population of school entrants were identified by their teachers as having emerging additional needs at the outset of school. These difficulties were associated with poorer literacy and numeracy outcomes at Grade 3, even after accounting for sociodemographic characteristics and, in sensitivity analyses, cognitive functioning. This 
effect is equivalent to around 9 months of schooling using the standards to which the UK Education Endowment Fund designs its school intervention trials (Education Endowment Foundation, 2018). Given the high stability of academic trajectories beyond the midelementary school years, these disparities in early academic skills are of considerable concern.

The current findings extend the current evidence by demonstrating that the well-recognized relationship between health and learning (Bethell et al., 2012; Forrest et al., 2011; Goldfeld et al., 2015; O'Connor et al., 2015; Pinquart \& Teubert, 2012; Reuben \& Pastor, 2013), also applies to emerging additional needs identified by teachers in the first year of school. Sensitivity analyses further indicated that this effect could not be explained by differences in children's cognitive functioning. Previous research has similarly observed that even conditions with no direct neurological impacts can be associated with learning outcomes. For example, children with behavioural difficulties often have poor academic outcomes despite normal cognition (Metsäpelto et al., 2015). Disruptive behaviours can result in children missing vital information, failing to follow teachers' instructions, avoiding classroom tasks or assignments, and having poorer relationships with their teachers, which can compound over time to result in significant consequences for their learning progress (Metsäpelto et al., 2015).

Access to appropriate health and education supports play an important role in preventing these poor outcomes (O'Connor et al., 2015). For example, evidence based approaches to managing behavioural difficulties in the classroom, such as positive behaviour support, can also help to improve children's academic progress (Horner et al., 2009). Yet, following the inverse care law, children living in disadvantaged circumstances have less access to such resources, including lower access to quality schools, resources that promote learning in the 
home, and specialist health services (Bradley \& Corwyn, 2002; Dalziel et al., 2018). The current findings suggest that as a result, the combined effect of socioeconomic disadvantage and emerging additional needs on children's academic learning is greater than their sum in isolation.

\section{Strengths and limitations}

This study draws on data from over 40,000 children, providing strong evidence of an association between teacher-identified emerging additional needs and academic outcomes. Quantifying outcomes specifically for children with emerging additional needs raises their visibility, and using teachers as informants is advantageous when aiming to capture functioning within the school context (Janus, Offord, \& Walsh, 2001; O'Connor et al., 2017; O'Connor et al., 2016). Nevertheless, a number of limitations should be born in mind. It would have been valuable to triangulate across teacher, parent and clinician perspectives on a child's need for additional support. Teacher reports of additional needs may miss those health and developmental issues that are primarily managed in the family or community context and may not be known by teachers. In addition, children's needs can change over time. We do not know whether additional needs had developed (or resolved) in the interval between the start of school and Grade 3 academic assessment, or what services and supports children received in the interim period.

\section{Implications and future directions}

Failure to fully capitalize on children's learning potential has serious social and economic repercussions. It should therefore be a priority to identify opportunities in the health and education systems to reduce gaps in learning outcomes for children with emerging additional needs, particularly for those children who are also disadvantaged. Flexible approaches are 
needed that can quickly respond to children's needs as they first arise. This includes wellcoordinated processes across the health and education settings to ensure an appropriate referral pathway when teachers have concerns, and appropriate feedback following assessment to ensure a shared understanding of children's needs and care (O'Connor et al., 2015). In the school setting, there is also a need to incentivise the use of evidence-based strategies, such as response to intervention approaches that employ a graduation of evidencebased interventions depending on the child's individual needs over time (Mitchell, 2014). The potentially amplifying effect of socioeconomic disadvantage further suggests the importance of increasing the intensity of these supports for those who are also disadvantaged (Carey, Crammond, \& De Leeuw, 2015). Health practitioners like paediatricians also play a vital role. When working with children with additional needs and their families, health practitioners can help to identify learning issues and make referrals to early intervention services, provide guidance for parents on how to create rich learning environments in the home, advocate for the use of evidence-based approaches, and coordinate supports over the health, education, and home contexts (Medical Home Initiatives for Children With Special Needs Project Advisory Committee, 2002).

\section{Conclusions}

A challenge facing education systems is how to best respond to children's health and developmental concerns as they first emerge in the school setting. In the current study, emerging additional health and developmental needs identified by teachers at the outset of schooling was associated with poorer literacy and numeracy skills at Grade 3, and family socioeconomic disadvantage appeared to further amplify this effect. Failure to support children's academic learning has potentially long term consequences for educational, occupational and health pathways over the life course. 


\section{REFERENCES}

Australian Bureau of Statistics. (2013). Australian Aboriginal and Torres Strait Islander Health Survey: First Results, Australia, 2012-13. Retrieved from Canberra: http://www.abs.gov.au/ausstats/abs@.nsf/Lookup/4727.0.55.001main+features80201 $\underline{2-13}$

Australian Curriculum Assessment and Reporting Authority. (2017). NAPLAN achievement in reading, persuasive writing, language conventions and numeracy: National report for 2017. Retrieved from https://www.nap.edu.au/docs/default-source/defaultdocument-library/naplan-national-report-2017_final_04dec2017.pdf?sfvrsn=0

Barnard-Brak, L., Stevens, T., \& Carpenter, J. (2017). Care Coordination with Schools: The Role of Family-Centered Care for Children with Special Health Care Needs. Maternal and Child Health Journal, 21(5), 1073-1078. doi:10.1007/s10995-016-2203-x

Bethell, C., Forrest, C., Stumbo, S., Gombojav, N., Carle, A., \& Irwin, C. (2012). Factors promoting or potentially impeding school success: Disparities and state variations for children with special health care needs. Maternal and Child Health Journal, 16, S35S43.

Bethell, C. D., Blumberg, S. J., Stein, R. E., Strickland, B., Robertson, J., \& Newacheck, P. W. (2015). Taking stock of the CSHCN screener: a review of common questions and current reflections. Academic pediatrics, 15(2), 165-176.

Bradley, R. H., \& Corwyn, R. F. (2002). Socioeconomic status and child development. Annual Review of Psychology, 53(1), 371-399. doi:http://dx.doi.org/10.1146/annurev.psych.53.100901.135233

Brinkman, S., Gregory, T., Goldfeld, S., Lynch, J., \& Hardy, M. (2014). Data resource profile: The Australian Early Development Index (AEDI). International Journal of Epidemiology, 43(4), 1089-1096. doi:http://dx.doi.org/10.1093/ije/dyu085

This article is protected by copyright. All rights reserved. 
Carey, G., Crammond, B., \& De Leeuw, E. (2015). Towards health equity: A framework for the application of proportionate universalism. International Journal for Equity in Health, 14, 81. doi:http://dx.doi.org/10.1186/s12939-015-0207-6

Dalziel, K., Huang, L., Hiscock, H., \& Clarke, P. (2018). Born equal? The distribution of government Medicare spending for children. Social Science \& Medicine.

Daraganova, G., Edwards, B., \& Sipthorp, M. (2013). Using National Assessment Program Literacy and Numeracy (NAPLAN) data in the Longitudinal Study of Australian Children (LSAC). Melbourne, Australia: Australian Institute of Family Studies.

Davis-Kean, P. E. (2005). The influence of parent education and family income on child achievement: the indirect role of parental expectations and the home environment. Journal of Family Psychology, 19(2), 294-304.

De Lemos, M., \& Doig, B. (1999). Who Am I? Developmental Assessment Manual. Retrieved from Melbourne:

Department for Education and Skills. (2001). Special educational needs and disability act. In: HMSO London.

Education Endowment Foundation. (2018). Sutton Trust-EEF Teaching and Learning Toolkit \& EEF Early Years Toolkit. Technical appendix and process manual. Retrieved from https://educationendowmentfoundation.org.uk/public/files/Toolkit/Toolkit_Manual_2 018.pdf

Forrest, C., Bevans, K., Riley, A., Crespo, R., \& Louis, T. (2011). School outcomes of children with special health care needs. Pediatrics, 128(2), 303-312. doi:10.1542/peds.2010-3347

Goldfeld, S., O'Connor, M., Quach, J., Tarasuik, J., \& Kvalsvig, A. (2015). Learning trajectories of children with special health care needs across the severity spectrum. 
Academic pediatrics, 15(2), 177-184.

doi:http://dx.doi.org/10.1016/j.acap.2014.09.001

Horner, R. H., Sugai, G., Smolkowski, K., Eber, L., Nakasato, J., Todd, A. W., \& Esperanza, J. (2009). A Randomized, Wait-List Controlled Effectiveness Trial Assessing SchoolWide Positive Behavior Support in Elementary Schools. Journal of Positive Behavior Interventions, 11(3), 133-144. doi:10.1177/1098300709332067

Hosmer, D., \& Lemeshow, S. (1992). Confidence interval estimation of interaction. Epidemiology, 3(5), 452-456.

Janus, M., Offord, D., \& Walsh, C. (2001). Population-level assessment of readiness to learn at school for 5-year-olds in Canada: Relation to child and parent measures. Paper presented at the SRCD Meeting, Minneapolis, US.

Knol, M., \& VanderWeele, T. (2012). Recommendations for presenting analyses of effect modification and interaction. International Journal of Epidemiology, 41(2), 514-520.

Liu, T., Lingam, R., Lycett, K., Mensah, F. K., Muller, J., Hiscock, H., . . Wake, M. (2018). Parent-reported prevalence and persistence of 19 common child health conditions. Archives of Disease in Childhood, 103(6), 548-556.

Medical Home Initiatives for Children With Special Needs Project Advisory Committee. (2002). The medical home. Pediatrics, 110(1), 184-186.

Metsäpelto, R.-L., Pakarinen, E., Kiuru, N., Poikkeus, A.-M., Lerkkanen, M.-K., \& Nurmi, J.-E. (2015). Developmental dynamics between children's externalizing problems, task-avoidant behavior, and academic performance in early school years: A 4-year follow-up. Journal of Educational Psychology, 107(1), 246.

Mitchell, D. (2014). What really works in special and inclusive education. Florence, United States: Taylor and Francis.

This article is protected by copyright. All rights reserved. 
O'Connor, M., Howell-Meurs, S., Kvalsvig, A., \& Goldfeld, S. (2015). Understanding the impact of special health care needs on early school functioning: A conceptual model. Child: Care, Health and Development, 41(1), 15-22. doi:http://dx.doi.org/10.1111/cch.12164

O'Connor, M., O'Connor, E., Quach, J., Vashishtha, R., \& Goldfeld, S. (in press). Trends in the prevalence and distribution of teacher-identified special health care needs across three successive population cohorts. Journal of Paediatrics and Child Health.

O'Connor, M., Rosema, S., Quach, J., Kvalsvig, A., \& Goldfeld, S. (2017). Special Health Care Needs Across the School and Family Contexts: Implications for Service Utilization. Academic pediatrics, 17(6), 687-693. doi:http://dx.doi.org/10.1016/j.acap.2017.02.012

O’Connor, M., Quach, J., Goldfeld, S., Gold, L., Aston, R., Beatson, R., \& Hopkins, D. (2015). Approaches to the provision of educational support for children and young people with additional health and developmental needs: Autism spectrum disorders. Melbourne, Australia: Centre for Community Child Health.

O’Connor, M., Rosema, S., Quach, J., Kvalsvig, A., \& Goldfeld, S. (2016). Parent and teacher perceptions of emerging special health care needs. Journal of Paediatrics and Child Health, 52(10), 950-956. doi:https://doi.org/10.1111/jpc.13188

Pinquart, M., \& Teubert, D. (2012). Academic, physical, and social functioning of children and adolescents with chronic physical illness: A meta-analysis. Journal of Pediatric Psychology, 37(4), 376-389. doi:10.1093/jpepsy/jsr106

Reuben, C. A., \& Pastor, P. N. (2013). The effect of special health care needs and health status on school functioning. Disability and Health Journal, 6(4), 325-332.

This article is protected by copyright. All rights reserved. 
Soloff, C., Lawrence, D., Misson, S., \& Johnstone, R. (2006). LSAC Technical paper No. 3. Wave 1 weighting and non-response. Melbourne, Australia: Australian Institute of Family Studies.

VanderWeele, T., \& Knol, M. (2014). A tutorial on interaction. Epidemiologic Methods, 3(1), 33-72. doi:https://doi.org/10.1515/em-2013-0005

White, I. R., Royston, P., \& Wood, A. M. (2010). Multiple imputation using chained equations: Issues and guidance for practice. Statistics in Medicine, 30(4), 377-399. doi:http://dx.doi.org/10.1002/sim.4067 
Table 1. Characteristics of the Victorian school entrant population $(\mathrm{N}=42,619)$.

\begin{tabular}{|c|c|c|}
\hline & $\mathbf{N}$ & $\begin{array}{c}\text { Mean (SD) } \\
\text { or \% }\end{array}$ \\
\hline \multicolumn{3}{|l|}{ Additional needs in the first year of school } \\
\hline Standard population & 32,291 & 75.78 \\
\hline Emerging needs & 8,293 & 19.46 \\
\hline Established needs & 2,055 & 4.77 \\
\hline \multicolumn{3}{|l|}{ Academic performance at Grade 3} \\
\hline Reading & 39,178 & $439.96(90.58)$ \\
\hline Numeracy & 39,184 & $411.71(80.70)$ \\
\hline \multicolumn{3}{|l|}{ Socio-demographic characteristics } \\
\hline \multicolumn{3}{|l|}{ Child's age at school entry ( 5 years) } \\
\hline Under 5 years & 405 & 1.00 \\
\hline 5 years & 33,744 & 79.18 \\
\hline Over 5 years & 8,470 & 19.87 \\
\hline \multicolumn{3}{|l|}{ Sex } \\
\hline Male & 21,906 & 51.40 \\
\hline Female & 20,713 & 48.60 \\
\hline \multicolumn{3}{|c|}{ Aboriginal and/ or Torres Strait Islander (ATSI) } \\
\hline Yes & 659 & 1.55 \\
\hline No & 41,960 & 98.45 \\
\hline \multicolumn{3}{|l|}{ Country of birth } \\
\hline Australia & 39,689 & 93.13 \\
\hline Overseas & 2,930 & 6.87 \\
\hline \multicolumn{3}{|l|}{ Community disadvantage (SEIFA) } \\
\hline Quintile 1 (most disadvantaged) & 6,094 & 14.30 \\
\hline Quintile 2 & 74,470 & 17.53 \\
\hline Quintile 3 & 9,422 & 22.11 \\
\hline Quintile 4 & 10,884 & 25.54 \\
\hline Quintile 5 (least disadvantaged) & 8,749 & 20.53 \\
\hline \multicolumn{3}{|l|}{ Language background other than English } \\
\hline Yes & 8,376 & 19.65 \\
\hline No & 34,243 & 80.35 \\
\hline \multicolumn{3}{|l|}{ Geographic location } \\
\hline Major cities or regional centres & 40,578 & 95.21 \\
\hline Outer regional or remote area & 2,041 & 4.79 \\
\hline \multicolumn{3}{|l|}{ Mother highest level of education } \\
\hline Completed high school or below & 11,663 & 28.15 \\
\hline Certificate/diploma/advanced diploma & 16,083 & 38.82 \\
\hline Bachelor degree or above & 13,682 & 33.03 \\
\hline \multicolumn{3}{|l|}{ Mother occupation } \\
\hline Not in paid work & 17,147 & 40.52 \\
\hline Clerical, sales, etc. & 13,033 & 30.79 \\
\hline Managers and professionals & 12,142 & 28.69 \\
\hline \multicolumn{3}{|l|}{ Father highest level of education } \\
\hline Completed high school or below & 8,700 & 24.81 \\
\hline Certificate/diploma/advanced diploma & 15,629 & 44.57 \\
\hline Bachelor degree or above & 10,737 & 30.62 \\
\hline \multicolumn{3}{|l|}{ Father occupation } \\
\hline Not in paid work & 4,856 & 13.37 \\
\hline
\end{tabular}


Clerical, sales, etc.

16,916

46.59

Managers and professionals

14,535

40.03

Note. These descriptive results show original data, exclusive of imputation.

This article is protected by copyright. All rights reserved. 
Figure 1. Areas of impairment identified by teachers for children with emerging health and developmental needs in the first year of school.

Speech impairment

Problems associated with home environment

Visual impairment

Behavioural problems

Emotional problems

Trauma

Learning disability

Hearing impairment

Physical disability

Other enduring problems

Requires further assessment
$18.1 \%$

$11.0 \%$

$10.2 \%$

$9.8 \%$

$6.0 \%$

$4.1 \%$

$4.1 \%$

$2.3 \%$ 
Table 2. Associations between teacher-identified additional needs in the first year of school and reading and numeracy outcomes at Grade 3 in the Victorian school entrant population $(\mathrm{N}=42,619)$.

\begin{tabular}{|ccccccc}
\hline \multicolumn{3}{c}{ Reading } & \multicolumn{3}{c}{ Numeracy } \\
\hline & $\begin{array}{c}\text { Unadjusted } \\
\mathrm{B}(95 \% \mathrm{CI})\end{array}$ & $\begin{array}{c}\text { Adjusted } \\
\mathrm{B}(95 \% \mathrm{CI})\end{array}$ & $\begin{array}{c}\text { Effect size } \\
(\mathrm{SD})\end{array}$ & $\begin{array}{c}\text { Unadjusted } \\
\mathrm{B}(95 \% \mathrm{CI})\end{array}$ & $\begin{array}{c}\text { Adjusted } \\
\mathrm{B}(95 \% \mathrm{CI})\end{array}$ & $\begin{array}{c}\text { Effect size } \\
(\mathrm{SD})\end{array}$ \\
\hline Additional needs & & & & & \\
Standard population & Ref & Ref & & Ref & Ref \\
Emerging needs & -40.62 & -26.86 & 0.29 & -32.79 & -24.39 & 0.30 \\
& $(-43.20,-38.03)$ & $(-29.19,-24.52)$ & & $(-35.02,-30.56)$ & $(-26.43,-22.35)$ & 0.49 \\
Established needs & -57.41 & -42.48 & 0.46 & -46.27 & -39.85 & 0.49 \\
& $(-62.67,-52.16)$ & $(-47.41,-37.55)$ & & $(-50.53,-42.00)$ & $(-43.90,-35.80)$ & \\
\hline
\end{tabular}

Note. Estimates show unstandardized beta coefficients. Adjusted for age at school entry, sex, country of birth, SEIFA, remoteness, language background other than English, mother's education, mother's occupation, father's education, and father's occupation. 
Table 3. Combined effect of additional health and developmental needs and maternal education on poor reading outcomes in the Victorian population cohort $(\mathrm{N}=42,619)$.

\begin{tabular}{|c|c|c|c|c|c|c|c|c|c|}
\hline & & \multicolumn{6}{|c|}{ Additional health and developmental needs } & \multirow{3}{*}{$\begin{array}{l}\text { RRs }(95 \% \mathrm{Cl}) \text { for } \\
\text { emerging needs } \\
\text { within strata } \\
\text { of maternal } \\
\text { education }\end{array}$} & \multirow{3}{*}{$\begin{array}{l}\text { RRs }(95 \% \mathrm{Cl}) \text { for } \\
\text { established needs } \\
\text { within strata } \\
\text { of maternal } \\
\text { education }\end{array}$} \\
\hline & & \multicolumn{2}{|c|}{ Standard population } & \multicolumn{2}{|c|}{ Emerging needs } & \multicolumn{2}{|c|}{ Established needs } & & \\
\hline & & $\begin{array}{l}\text { N low reading* / } \\
\text { high reading }\end{array}$ & $\mathrm{RR}(95 \% \mathrm{Cl})$ & $\begin{array}{l}\text { N low reading / } \\
\text { high reading }\end{array}$ & $\mathrm{RR}(95 \% \mathrm{Cl})$ & $\begin{array}{l}\mathrm{N} \text { low reading / } \\
\text { high reading }\end{array}$ & $\mathrm{RR}(95 \% \mathrm{Cl})$ & & \\
\hline Maternal & Higher & $3474 / 20434$ & 1.00 (ref) & $1482 / 3888$ & $1.82(1.72,1.93)$ & $447 / 853$ & $2.23(2.03,2.44)$ & $1.79(1.69,1.90)$ & $2.23(2.02,2.45)$ \\
\hline & Lower & $2168 / 6215$ & $1.76(1.67,1.85)$ & $1334 / 1589$ & $2.96(2.81,3.13)$ & $403 / 332$ & $3.47(3.17,3.81)$ & $1.73(1.62,1.83)$ & $2.03(1.84,2.23)$ \\
\hline $\begin{array}{l}\text { RRs } 195 \% \\
\text { within stra }\end{array}$ & $\begin{array}{l}\text { for mate } \\
\text { f needs }\end{array}$ & al education & $1.77(1.68,1.86)$ & & $1.64(1.54,1.75)$ & & $1.58(1.40,1.78)$ & & \\
\hline Measure & teraction & additive scale: R & $\mathrm{VI}(95 \% \mathrm{Cl})$ & $2.96-1.82-1.76+1$ & $=0.38(0.22,0.55)$ & $3.47-2.23-1.76$ & $=0.48(0.14,0.83)$ & & \\
\hline $\begin{array}{l}\text { Measure } \\
\text { Ratio of } R\end{array}$ & $\begin{array}{l}\text { teraction } \\
(95 \% \mathrm{Cl})\end{array}$ & odification on mult & licative scale: & $2.96 /(1.82 * 1.76)$ & $0.92(0.85,1.00)$ & $3.47 /\left(2.23^{*} 1.7\right.$ & $=0.88(0.78,1.00)$ & & \\
\hline
\end{tabular}

Ratio of RRs $(95 \% \mathrm{Cl})$

*low reading/numeracy = bottom 20\%. RRs are adjusted for age at school entry, sex, country of birth, remoteness, language background other than English

Lower education (completed high school or below) 28\%; Higher education (certificate/diploma/bachelor) $72 \%$.

This article is protected by copyright. All rights reserved. 
Table 4. Combined effect of additional health and developmental needs and maternal education on poor numeracy outcomes in the Victorian population cohort

$(\mathrm{N}=42,619)$.

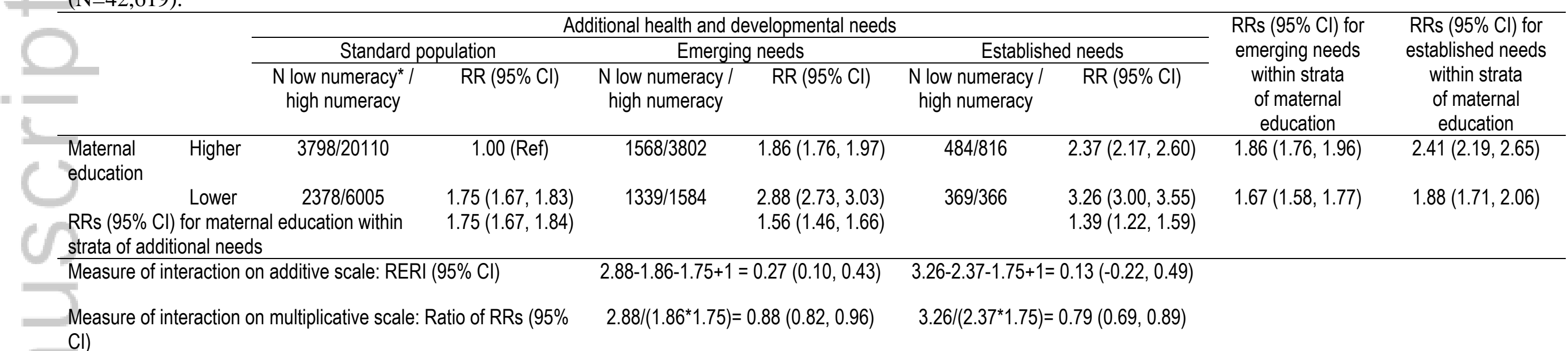

*low reading/numeracy = bottom 20\%. RRs are adjusted for age at school entry, sex, country of birth, remoteness, language background other than English. Lower education (completed high school or below) 28\%; Higher education (certificate/diploma/bachelor) $72 \%$.

This article is protected by copyright. All rights reserved. 


\section{University Library}

\section{- M M I N E R VA A gateway to Melbourne's research publications}

Minerva Access is the Institutional Repository of The University of Melbourne

Author/s:

O'Connor, M;Chong, S;Quach, J;Goldfeld, S

Title:

Learning outcomes of children with teacher-identified emerging health and developmental needs.

Date:

2020-03-01

Citation:

O'Connor, M., Chong, S., Quach, J. \& Goldfeld, S. (2020). Learning outcomes of children with teacher-identified emerging health and developmental needs.. Child: Care, Health and Development, 46 (2), pp.223-231. https://doi.org/10.1111/cch.12737.

Persistent Link:

http://hdl.handle.net/11343/276825 